\title{
DECONSTRUCTING QUESTIONS: REANALYZING A HETEROGENOUS CLASS OF SPEECH ACTS VIA COMMITMENT AND ENGAGEMENT
}

\author{
Johannes M. Heim \\ University of Greifswald \\ johannes.heim@uni-greifswald.de \\ Martina E. Wiltschko \\ ICREA, Universitat Pompeu Fabra \\ martina.wiltschko@icrea.cat
}

\begin{abstract}
Direct and indirect characterizations of the relation between clause type (syntactic form) and speech act (pragmatic function) are problematic because they map oversimplified forms onto decomposable functions. We propose an alternative account of questions by abandoning any (in)direct link to their clause type and by decomposing speech acts using two variables encoding propositional attitudes. One variable captures the speaker's commitment to an utterance, another their expectation toward the addressee's engagement. We couch this proposal in a syntactic framework that relies on two projections dedicated to managing common ground (GroundP) and managing turn-taking (ResponseP), respectively. Empirical evidence comes from the conversational properties of sentence-final intonation in English and sentence-peripheral particles that serve to manage the common ground.
\end{abstract}

Key words: speech act, commitment, engagement, grounding, intonation, particles 


\section{Questions do not form a natural class}

Questions have conversational effects that seem straightforward to define. Searle (1969), for instance, defines them as attempts to elicit information from the hearer. In this paper, we investigate the relation between the forms and functions of different types of questions with the aim of identifying what these types have in common and whether they can be assumed to form a natural class. Specifically, we address three problems that arise from characterizations of questions in the previous literature: (i) the identification of marked and unmarked forms of questions; (ii) the unification of different types of questions; and (iii) the mapping of forms and functions in the context of questions. We address these problems by arguing for a new typology of questions that conceptualizes questions as different configurations of speaker commitment and addressee engagement. The former captures the epistemic stance of the speaker, the latter their expectation toward the addressee on what to do with the question. Both variables are independent of the notion of questionhood and can be applied to a range of speech acts that cannot be described as attempts to elicit information. They nevertheless share important properties with the notion of questionhood. As a result of our reanalysis, we argue that the many phenomena associated with questionhood do not form a natural class. This provokes the question of what questions really are and how to differentiate them from other speech acts. Our central claim is that questions can be deconstructed and analysed with the same conversational variables as other types of speech acts.

As a somewhat representative sample of English phenomena associated with questionhood in the literature, consider the data in (1) and (2). These examples are constructed as minimal pairs to allow us to limit the factors of variation to consider in our analysis. They correspond to naturally occurring data discussed in corpus-based analyses (see Hedberg et al. 2017 for authentic examples of the different variants of polar questions and content questions, and Bolinger 1957 for authentic examples of echo questions and alternative questions). We follow Bartels (1997) in only considering syntactically complete sentences. Fragments and embedded speech acts will have to await future investigation. In the presentation of our examples, we avoid punctuation marks - which take the notion of questionhood to be self-explanatory - and include arrows that represent the shape of sentence-final intonation (henceforth SFI). We also provide tone ToBI annotations following the official guidelines in Silverman et al. 2012, which build on high and low tones exclusively.
a. Who won $\downarrow$
$\left(\mathrm{H}^{*} \mathrm{~L}-\mathrm{L} \%\right)$
b. She won WHAT $\uparrow$
$\left(\mathrm{L}^{*}+\mathrm{H} \mathrm{H}-\mathrm{H} \%\right)$
c. Who won (again) $\uparrow$
$\left(\mathrm{L}^{*} \mathrm{H}-\mathrm{H} \%\right)$ 
(2)
a. She won $\uparrow$
( $\left.\mathrm{L}^{*} \mathrm{H}-\mathrm{H} \%\right)$
b. Did she win $\uparrow$
$\left(\mathrm{L}^{*} \mathrm{H}-\mathrm{H} \%\right)$
c. Did she win or loose $\downarrow$
$\left(\mathrm{H}^{*} \mathrm{~L}-\mathrm{L} \%\right)$

All questions in 1 contain a wh-pronoun and none of the questions in 2 do. This suggests an initial categorical distinction in English questions. We argue, however, that the differences between the data in 1 and 2 as well as the similarities across them make a categorical distinction of question types as challenging as finding a common denominator for all of them. We depart from a form-based notion of questionhood and primarily rely on function for our analysis. This function-based analysis leads us to conclude that the phenomena in 1 and 2 are so different that they cannot be members of a singular natural class. Instead, they can be classified according to the same dimensions as other phenomena that serve to manage the common ground (Stalnaker 1978).

We couch our analysis based on commitment and engagement in a formalist framework, which employs syntax as a mediator of form and function. Following Wiltschko's (2014) Universal Spine Hypothesis (USH), we rely on a cross-linguistically uniform architecture that relates different functions in a sentence. The USH broadly follows the generative tradition (Chomsky 1995) in assuming a syntactocentric model of grammar which relies on a hierarchically organized structure that configures sentences. On top of the clausal structure (CP), we assume two additional projections, a Grounding Phrase (GroundP) and a Response Phrase (ReponseP), which both scope over the proposition (Wiltschko \& Heim 2016, Wiltschko 2017). These projections host the Units of Language expressing commitment and engagement (see Figure 1), which regulate the management of common ground and the management of turntaking. Each of those projections can be independently motivated by the clause type restrictions of discourse particles (Heim et al. 2016; Yang \& Wiltschko 2018, Heim 2019a) and the interpretation of several intonational contours in English (Heim 2019b).

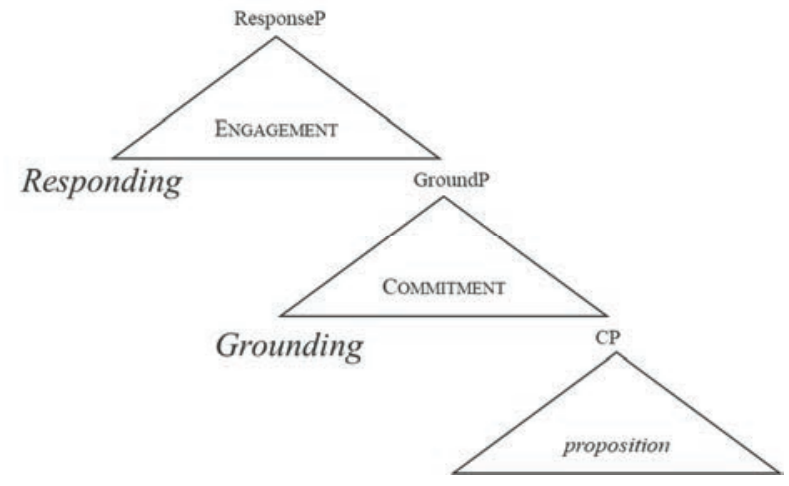

Figure 1: Syntactic integration of commitment and engagement 
We define the function of questions and other speech acts in terms of conversational effects. Speech acts serve to enrich the common ground (Stalnaker 1978) in the form of a collaborative effort that minimally consists of an initiation and a reaction phase (see also Clark \& Brennan 1991 who assume a distinction between a presentation and an acceptance phase). This effort is dynamic in the sense that a speaker projects the future development of the conversation (Auer 2002, Farkas \& Bruce 2010, Malamud \& Stephenson 2014, Stalnaker 2014). We consider this combination of actual and projected common ground management a reflex of Austin's (1962) distinction of illocution and perlocution. Since they became an object of study in modern linguistics, speech acts have marked the intersection between what speakers intend with their linguistic performances and what hearers make out of them (Lee 1974). Hence, any functional definition of questions needs to address how linguistic forms map onto intended meanings, and how these intended meanings result in performative acts.

We develop our argument as follows: We begin by discussing the form and function of a range of phenomena in English which are associated with the linguistic notion of questionhood (see Nielsen (2020, this issue for an overview of the phenomena associated with questionhood). We also provide a brief overview of the standard approach to model the mapping of their forms onto their functions. We then propose to characterize questions by their function independent of the formal descriptions influencing these previous accounts. We argue that questions need to be decomposed into different configurations of commitment and engagement. Next, we show how a syntactic integration of these variables can overcome the mapping problems of previous accounts. With syntax as a mediator of form and function, we have the means to model speech acts as complex phenomena that relate both speaker and addressee to the propositional content. We then show how our account can derive different types of questions in English. We conclude by revisiting the question of encoding the functions of the various questions, taking into consideration the contribution of sentence-final intonation (SFI).

\section{Forms, Functions, and Form-Function-Mappings of Questions}

In this section, we provide a brief overview of the forms and functions typically associated with questions. After pointing out some variation in the encoding of questions both with and without wh-pronouns, we discuss the functions of various types of questions with respect to their response requirements. We then turn to previous accounts of form-function mappings of questions which often turn to context as a modifier of these mappings. We demonstrate that these accounts are based on oversimplified mappings and fail to explain how context derives the indirect mappings. This survey serves as a motivation for developing our own account of questionhood. 
The empirical problem at hand, which we refer to as the speech act problem, has recently received considerable attention (e.g. Beyssade \& Marandin 2007, Farkas \& Roelofson 2017, Rudin 2018) in response to earlier, more direct approaches to the mapping of form and function (Sadock 1974, Levinson 1983). The common denominator of these accounts is that they distinguish between marked and unmarked forms of questions which map unto standard and derived functions of questions, respectively. We illustrate this in Figure 2: A combination of declarative clause type and falling SFI is considered an unmarked encoding of a standard assertion; a combination of interrogative clause type and rising SFI as in (2)b is considered an unmarked encoding of a standard question. Derived questions with a marked form are those speech acts that combine a declarative with rising SFI as in (2)a or an interrogative form with a falling SFI as in (2)c.

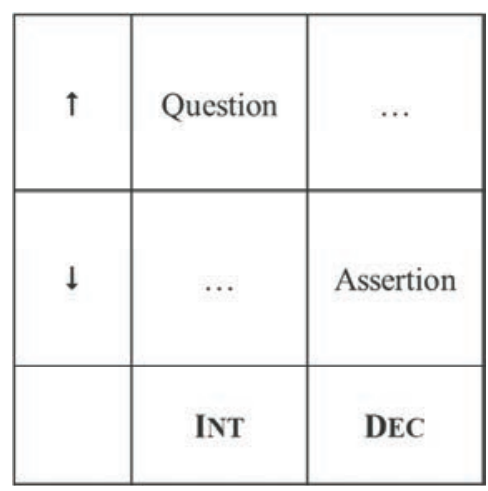

Figure 2: Simplified form-function mapping

Following the rationale represented by Figure 2, it would be possible, as one anonymous reviewer remarks, to establish a comprehensive typology of question. Such a typology would be based on a set of linguistic features (X) that map onto an attempt to elicit information characterized by a particular set of possible answers $(\mathrm{Y})$ in context $(\mathrm{C})$. Context hereby emerges as a default explanation for every indirect mapping of forms and function. We consider each of these variables in turn.

A comparison of the linguistic features in 1 and 2 shows significant variation both within and across different question types. This variation suggests that it is difficult to build the notion of questionhood on strictly form-based criteria. As for word order and intonation, which have played a prominent role in formal treatments of questions, we find considerable variation within the two groups above. Example (1)a includes a clause-initial wh-pronoun, but no subject-auxiliary-inversion (SAI). Example (1)b contains a wh-pronoun, but in its in-situ (non-initial) position, and no SAI. Both (1)b and (1)c occur with rising SFI while (1)a typically occurs with a falling SFI. In brief, neither SAI nor SFI is a reliable cue to identify the unmarked encoding of questions including 
a wh-pronoun. Based on form alone, these questions do not form a natural class. Questions without a wh-pronoun, show the same pattern: Example (2) a occurs without SAI, but with rising SFI; Example (2)b occurs with both SAI and with rising SFI; Example (2)c occurs with SAI, but with falling SFI. Even if we allow for a different encoding of information and polarity questions, the data in (1) and (2) reveal that it is difficult to identify any single unmarked form of questions. This is all the more true for the encoding of the overall category of questions: there is no configuration involving SAI, rising SFI, or wh-pronouns that would reliable identify a question as a question. While all examples in in (1) and (2) have been identified as questions in the literature, their form does not suggest that they form a natural class. The possible objection that different questions are encoded by different forms (e.g. whpronouns or SAI or SFI) is only as good as a definition of questionhood that can show that these questions have one central function identifying them as belonging to an overall speech act category of questions.

To understand what such a central function could be, we need to turn to the functions of the different types of questions and look for a common denominator. Yet, a function-based notion of questionhood that allows the different subtypes to be unified seems equally out of reach - despite a longstanding pursuit to do so. Semanticists generally argue that the function of a question is defined by the characteristics of their answers (Montague 1973), the truth values of these answers (Hamblin 1958) or the set of true answers (Karttunen 1977). Pragmaticists have associated this function with a (covert) operator (Stenius 1967) or a performative predicate (Lewis 1970), which turns the propositional content of a question into a directive speech act that requests information from the addressee (Searle 1975; see also Borchmann 2020 (this issue) for an account of Searle's analysis and classification). If we revisit the questions (Qs) in (1) and (2), and include possible answers (As), we note that a functional account of questionhood based on possible answers also faces serious challenges.
a. Q: Who won $\downarrow$
A: Ada Hegerberg.
b. Q: She won what $\uparrow$
A: I said she won the Ballon D'Or
c. Q: Who won (again) $\uparrow$
A: Marta, of course.
a. Q: She won $\uparrow$
A: Yes, I can't believe she did!
b. Q: Did she win $\uparrow$
A: Yes, that's right.
c. Q: Did she win or lose $\downarrow$
A: She won!

(4) 
At first glance, a categorical distinction between the questions in (3) and those in (4) based on the presence of a wh-pronoun seems to match their different response properties, thereby lending credit to an answer-based approach to their functions. Each question in (3) requires from the addressee to supply a missing piece of information identified by the wh-pronoun. Each question in (4) requests a selection among possible alternatives (which could be more than two in (4)c, of course). The set of possible answers considered by the speaker is always an exhaustive set of alternatives corresponding to the alternatives named in (4)c (Westera 2017). We assume that the answer sets are similarly restricted in (4)a and (4)b - here corresponding to polar opposites. This exhaustive marking of the response set is absent in (3). Of course, the addressee can expand the set in 4 , just as s/he can cancel the presupposition that somebody won something in 3 . Yet, the expansion of the set of alternatives in 4 comes at the price of marking this prosodically, for instance with a risefall-rise contour (Westera 2019). Both types of questions seem to serve as requests for information - either about the truth of a proposition or for a missing detail. A closer look at the individual examples, however, reveals that this binary distinction is artificial. The answer in (3)a selects one alternative from a non-exhaustive set of alternatives (Hausser 1983). The answer in (3) b reveals that the question refers to all-given material (Artstein 2002, Reis 2017), which impacts the set of alternatives. The answer in (3)c reminds the person asking the question that there was only one alternative at stake in the first place - thereby opening a side topic of the conversation (Hedberg et al. 2017). The answer set therefore is different for every type of content question in (3). We see the same pattern in (4): While the question in (4)b fits the description of a choice between an exhaustive list of alternatives, (4)a and (4)c are different. Example (4)a has the same set of alternatives as a polar question, but there is a bias towards the positive valuation of the truth values. Example (4)c asserts the choice of alternatives, but here there is no such bias. Just as with questions containing wh-pronoun, then, the variation in answers to the different questions without a wh-pronoun in (4) suggest that they fulfill different functions. Together with our observations on the variation in form, our analysis of the functions of questions based on set of possible answers brings us to the conclusion that a form-function mapping must be complex: It is impossible to uniquely map one particular set of linguistic features on one particular function based on possible answers.

A possible way to salvage a direct mapping of form and function may rely on context. Bartels (1997) and Truckenbrodt (2012), for instance, rely on the notion of salient propositions to explain why content questions and so-called high-rise questions (Hirschberg \& Ward 1992) have different effects than rising polarity questions. Since neither type has a typical question-rise ( $L^{*}$ $\mathrm{H}-\mathrm{H} \%)$ the accounts of intonational meaning of these authors need to rely on context to explain the questioning function. This notion of salient propositions, 
which allows an unconstrained impact of contextual information on the interpretation of a question, points to a central problem of including context as a variable in our definition of questions: it passes the onus of interpretation onto the addressee. Questions are only questions if the addressee considers context to sufficiently support a question interpretation. While contextual information certainly plays a role in deriving speech acts, we argue that its relation to the interpretation of questions lacks a systematic treatment that makes clear predictions of when context impacts a question interpretation and when it does not. We therefore include contextual information in our analysis of the different types of questions only to the extent that it explains the speaker's evidential basis for commitment (see below).

The preceding discussion of the forms and functions of the questions in (1) and (2) points to variation in the phenomena associated with questionhood within linguistics independent of whether they contain a wh-pronoun or not. If we cannot identify particular forms to uniquely define a question, and if we cannot constrain the definition of what is requested, a conception of questions as a natural class is untenable. We would have to define questionhood to be as broad as saying that a question is an attempt to elicit information. A simple directive as Tell me your name! shows that such a definition notably overgenerates. We suggest that this is an unsatisfying solution because it leaves us without any criteria to determine what counts as a question and without any means of creating a typology that only encompasses questions. A satisfying outcome would be to apply the notion of questionhood to a set of constructions that have a single common denominator which can be defined in terms that allow to exclude overgeneration and hence is specific enough to uniquely identify the members of that set. If such common denominator cannot be identified, the emerging typology is incompatible with the assumption that there is a natural class of questions. Different types of questions must then be considered different speech acts.

\section{Different questions have different configurations of commitment and engagement}

It is often claimed that a small set of forms map onto a small set of illocutionary functions in many unrelated languages (Sadock \& Zwicky 1985, Portner 2004, Allan 2006). These functions are said to be the essential building blocks of our conversations. Questions, in particular, serve both to structure our conversations (Roberts 1996) and to enhance the extent of our shared beliefs (Stalnaker 1978, 2002). Despite the challenges of adequately describing the form and function of questions and their form-function-mappings, then, we submit that there is something so intuitive about the notion of questionhood that is seems unwise to completely abolish it. We therefore aim in this paper to reconceptualize questions as interactional acts that relate speaker and addressee to a choice between propositional alternatives. We propose 
that what the different types of questions have in common is not unique to questionhood. Rather, the phenomena associated with questionhood are defined by two variables that also define different types of assertions. Each move in a conversation communicates the speaker's attitude to what they say and their intention of how the addressee should relate to it. Thus, we argue that all of the speech acts labeled as questions or assertions can be decomposed into these variables "speaker commitment" and "addressee engagement". This deconstruction of questions and assertions is possible by employing the syntactic module that mediates between form and function. Here we develop a syntactic account that builds on relating the propositional content to the interlocutors.

Mediating the relation between form and function is at the core of syntax. It is only through syntactic composition, that we can understand why the same form may be associated with different functions despite lexical identity: the difference in function correlates with different positions along the syntactic spine (see Wiltschko 2014, Wiltschko et al. 2018). Consider, for example, the multifunctionality of the English word have, which is employed both as an auxiliary and as a main verb. In (5), we see that the position on the syntactic spine determines its function. Have can either occur in the Tense Phrase of in the Verb Phrase. Depending on its location in the syntactic spine, the same form fulfills two functions.

$$
\text { Multifunctionality of have }
$$

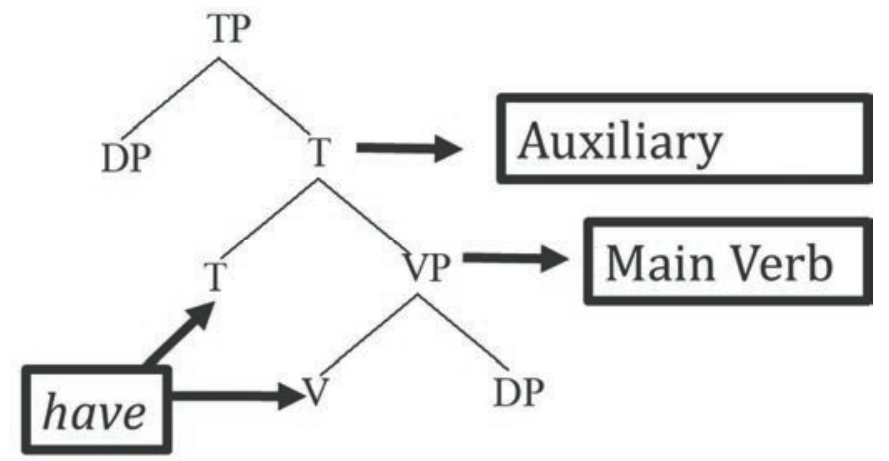

We see the same effect with German was, which can be employed both as a question word and as an indefinite pronoun (where it can also be realized as etwas). Their close relationship is a cross-linguistically pervasive phenomenon (Bhat 2001). Consider the minimal pair in (6) and (7), where the interpretation of was depends on its distribution. Sentence initial was in (6) has moved from a complement position in the Verb Phrase (VP) to a specifier position in the Complementizer Phrase (CP) and is interpreted as a question pronoun. In (7), was is hosted in the voice Phrase (vP) and is interpreted as an indefinite pronoun. 
$\left[_{\mathrm{CP}}\right.$ Was [C hat $\left[_{\mathrm{TP}}\right.$ die Schlange $\left[_{\mathrm{T}}\right.$ hat $\left[_{\mathrm{VP}}\right.$ gefressen $\left.\left.\left.\left.\mathrm{was}\right]\right]\right]\right]$

'What did the snake eat?'

$\left[_{\mathrm{CP}}\left[{ }_{\mathrm{TP}}\right.\right.$ die Schlange $\left[_{\mathrm{T}}\right.$ hat $\left[\mathrm{vP}\right.$ was $\left[_{\mathrm{VP}}\right.$ gefressen $\left.\left.\left.]\right]\right]\right]$

'The snake ate something.'

This suggests that the syntactic spine adds something to the interpretation of individual (lexical) forms. We refer to this as the substantivist view of syntax: the substance of structure adds meaning to words. The alternative to this view would be to postulate a series of lexical entries to capture the multi-functionality of Units of Language. But on such an approach there is no principled way to capture the types of multi-functionality observed. This is undesirable as multi-functionality is systematically related to syntactic distribution.

Clear evidence for the substantivist view of syntax comes from thetarole assignment where the position in the spine determines the role of the nominal argument. In (8), we see the same structural distribution as in (6) and (7): the same nominal fulfills different functions depending on where it occurs in the syntactic spine. The higher argument is assigned the role of an agent; the lower argument that of a patient. Syntax assigns the theta-roles in vP and VP (Williams 1981, 1994).

Theta-role assignment

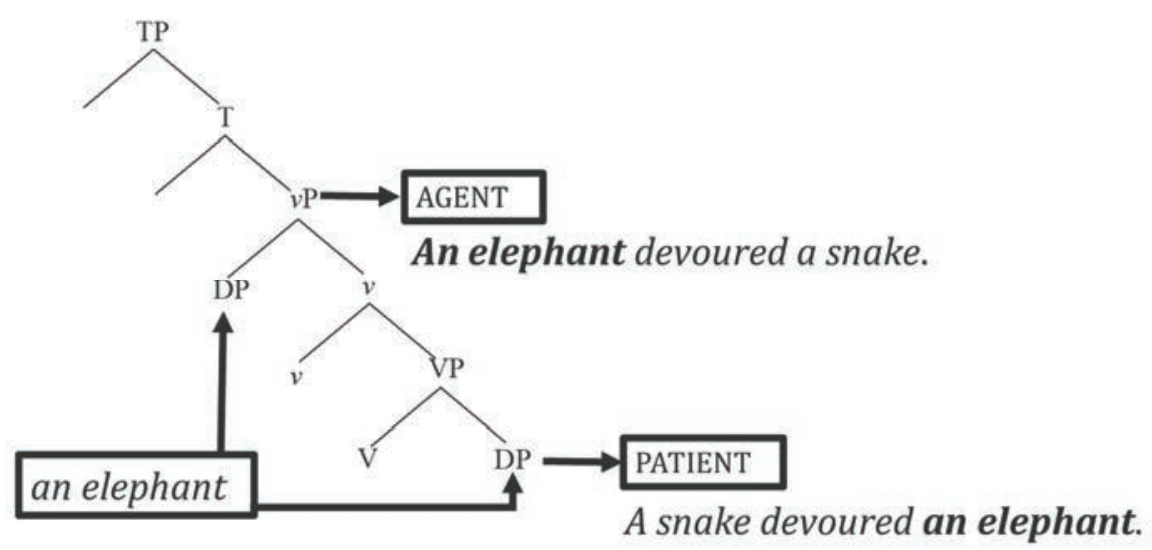

This substantivist view of syntax is captured by the Universal Spine Hypothesis in Wiltschko (2014), who argues that functional projections are universally associated with a core function. This core function is supplied by the spine and provides the added meaning described in (6) and (7). Universally, we see that form and function are mediated by a hierarchically-structured building plan, which captures the classification of events (in the theta structure), their point of view and anchoring (in the A-structure) and their linking to the context (in 
the A'-structure). Building on previous work on response particles (Wiltschko 2017) and discourse particles (Heim et al. 2016, Wiltschko \& Heim 2016), we extended the universal spine to incorporate an interactional structure, which is responsible for common ground- and turn-taking management (Wiltschko, to appear). The former is hosted in ResponseP, which serves both to project responses and contribute to a conversation with response particles, such as yes and no; the latter is hosted in GroundP, which serves to capture the interlocutors' attitude towards the proposition. The resulting structure is represented in Figure 3, including both structural labels and functions.

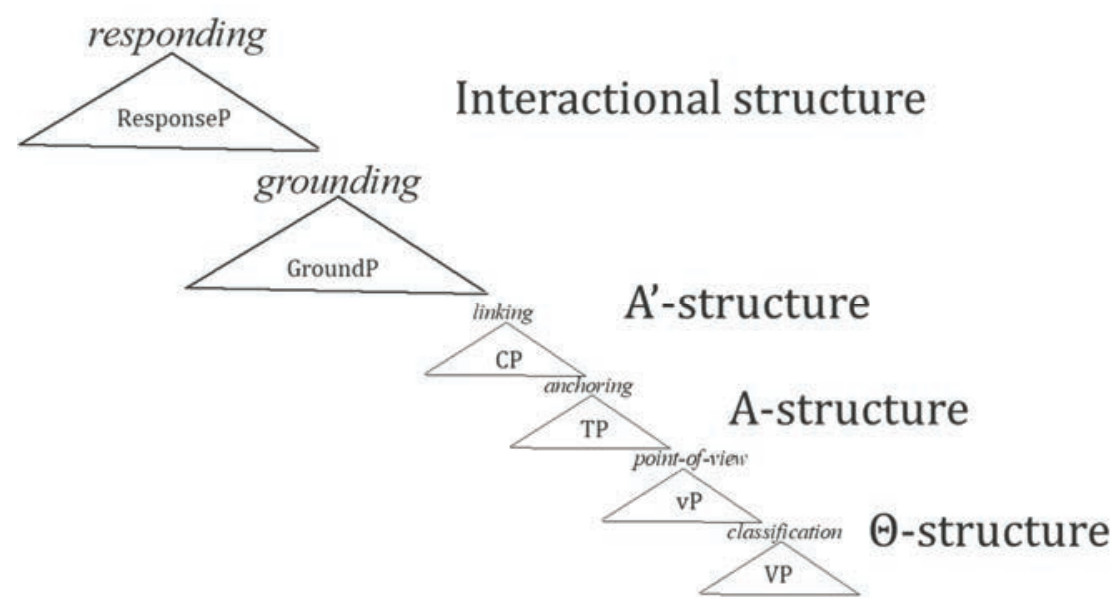

Figure 3: The extended spine provides substantive meaning

This way to syntactize speech acts goes beyond earlier attempts to derive speech acts syntactically as in Ross's (1970) performative hypothesis or the more recent attempts by Speas \& Tenny (2003) and Haegeman \& Hill (2013). In these earlier attempts, the structural layers responsible for interaction relate the interlocutors to the propositional content by mirroring the performative effect of a speech act (i.e. something along the lines of Ross's "I tell you that ..."). Instead of taking this literal approach to a syntactization of speech acts, we take the propositional content to be related to the beliefs of the speaker in GroundP. This relation is then communicated to the addressee via the ResponseP, which hosts a call on the addressee (Beyssade \& Marandin 2006) to engage with the speaker's ground. The key innovation in our account of speech acts, then, is the assumption that the speaker simultaneously signals both their propositional attitude and their expectation toward the addressee of what to do with the utterance. We can trace these functions for discourse particles (9) and response particles (10) separately. 

a. She won, didn't she?
b. She won, $\{$ eh/right $\}$ ?
a. $\quad\{$ So/well $\}$, she won.
b. Yeah, no, she won.

The interactional structure supplies a host for both of these components. In (9)a, for example, the tag itself encodes the propositional attitude. It is the rising SFI, however, that turns (9)a into a request to confirm the truth of the proposition. The composition of this two-fold message is visualized in Figure 4.

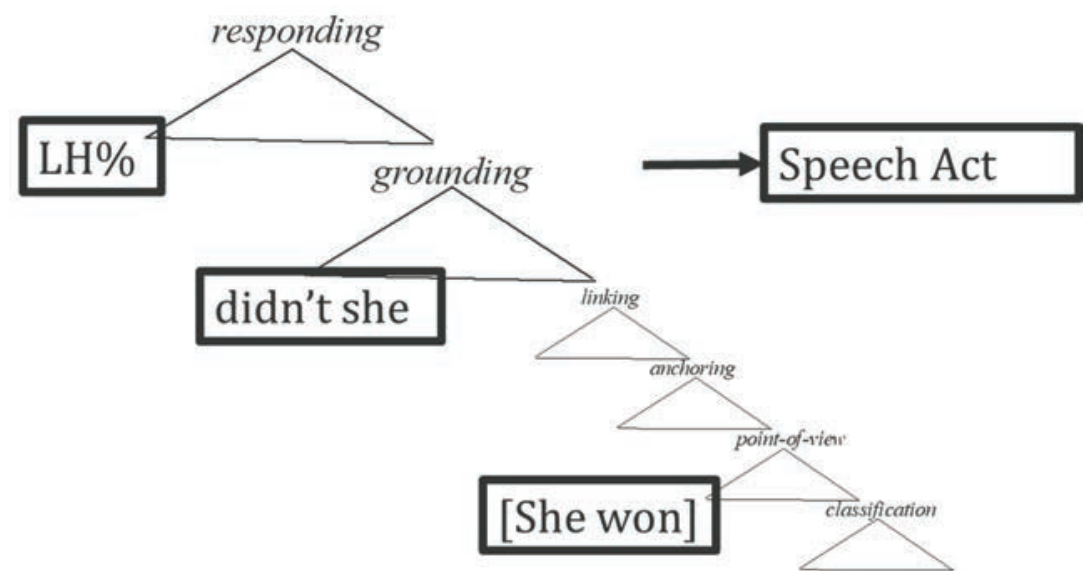

Figure 4: Decomposing tags into their responding and grounding aspects

The syntactictization of speech acts as illustrated in Figure 4 decomposes what other accounts take to be two sides of the same coin. Responding and grounding are both essential ingredients of questionhood, and syntax provides the means to relate them to the propositional content. Tag questions and intonation, which contribute two separate effects, make visible how grounding and responding relate to the rest of the sentence. We refer to the act of grounding as "commitment" and to the act of projecting a response as "engagement". Commitment can be defined in terms of the speaker's readiness to publicly commit to the truth of a proposition with the risk of social sanctions if the propositions turns out to be false (MacFalane 2011, Krifka 2015). Engagement can be defined as the speaker's expectation of how the addressee will respond to the speaker's utterance (Heim \& Wiltschko in press). To understand how commitment and engagement can derive different speech acts, consider first the example in (11). Assertions, such as (11), often constitute the default case in speech act models.
She won $\downarrow$
$\left(\mathrm{H}^{\star} \mathrm{L}-\mathrm{L} \%\right)$ 
Classic speech act theory assumes that an assertion has two effects: i) to communicate a belief, and ii) to share this belief (Bach \& Harish 1979). The process by which the speaker's belief is integrated by the addressee into his belief sets can be described as grounding. Grounding is defined by Bavelas et al. (2012: 1) as "the fundamental, moment-by-moment conversational process by which speaker and addressee are constantly establishing mutual understanding". It is important to recognize, however, that grounding is complex. Before a belief can be grounded, it may be necessary to negotiate it over several turns. At the very least, it needs to be accepted in a response move by the addressee, because the speaker cannot directly access the ground of the addressee (Clark \& Brennan 1991, Stalnaker 2001). Figure 5 visualizes the two phases, which we refer to as Initiation and Reaction. During Initiation, the speaker (S) tables their belief Bel (S,p), which is registered by the addressee (A). For Bel(p) to enter the Common Ground, however, it is necessary for the addressee to acknowledge that they share the speaker's belief. This is done by tabling their belief (Bel A,p).

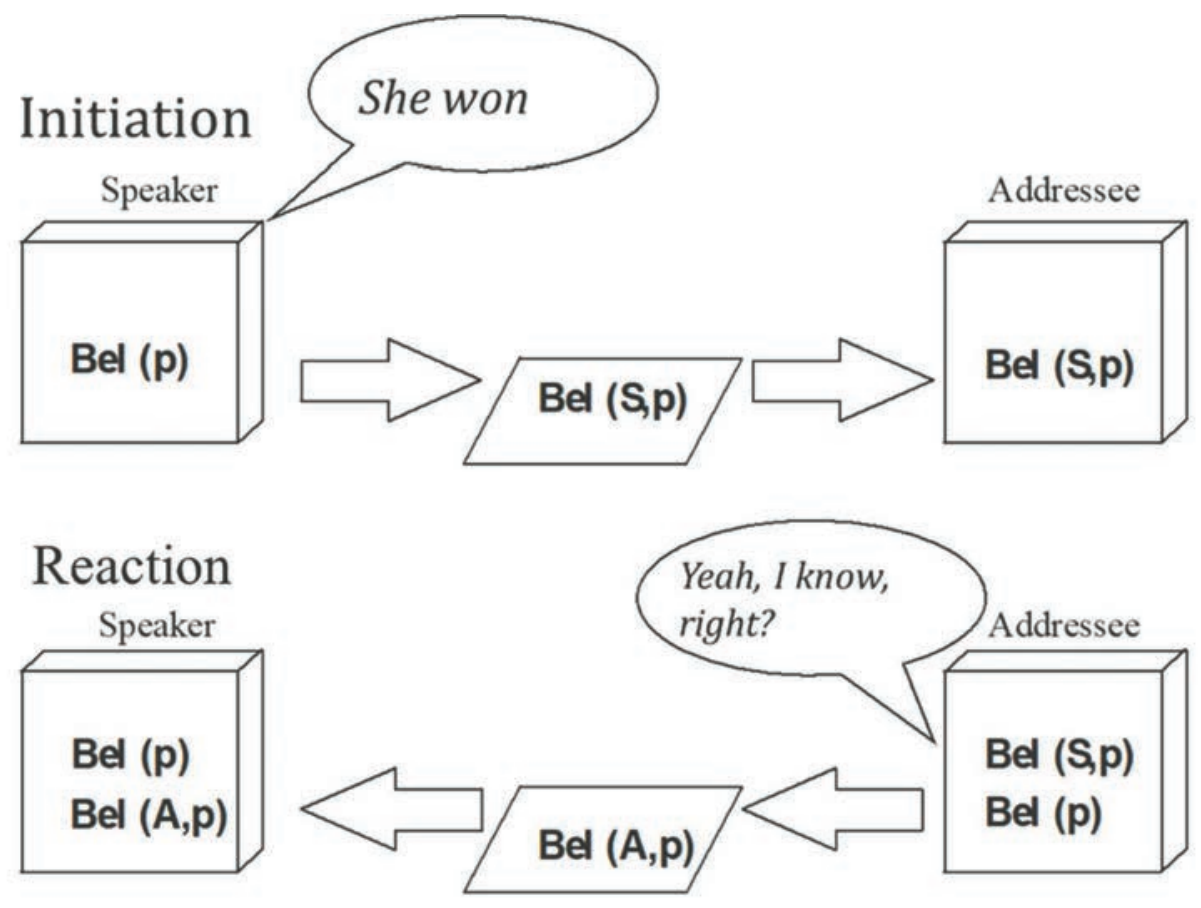

Figure 5: Negotiating an asserted belief (adapted from Wiltschko \& Heim 2016)

A crucial assumption of our analysis is that the reaction is anticipated by the speaker in their initiation turn. The speaker projects the continuation of the conversation (Auer 2002, Malamud \& Stephenson 2014), which is why each speech act makes two separate contributions: one in which the attitude toward the proposition is expressed and one in which the expectation of what will happen next is expressed. The innovation in our account is that 
both aspects can be communicated independently, namely through different particles and SFI. This may raise the question of the importance of pragmatic inferencing, which is often at the center of accounts on speech acts and also on intonational meaning. We submit that the speaker is never in control over the perlocutionary act. Yet the speaker has a host of means to propose an interpretation of the illocutionary act. Pragmatic inferencing is notably reduced if the speaker communicates their attitudes and intentions via particles, SFI, facial expressions or gestures.

\section{Polarity questions: An inverse relation of commitment and engagement} Commitment and engagement are in an inverse relationship in rising polar interrogatives. For these polarity questions, the speaker cannot commit to the truth of the proposition because they face a choice of an exhaustive set of propositions ( $\{p, \neg p\}$ ). Furthermore, the speaker engages the addressee to resolve the issue under negotiation. This configuration of commitment and engagement originates in a lack of evidence, which leads to a dependence of the speaker on the addressee in terms of their beliefs. Assertions have the opposite configuration, since here, the speaker has sufficient evidence to commit to a proposition and does not depend on the addressee for a verification of their beliefs (see Gunlogson 2008).

Questions with interrogative clause type and rising SFI have contexts of use that are defined by a clear asymmetry in knowledge between speaker and addressee. Likewise, assertions with declarative clause type and falling SFI are also defined by this asymmetry, albeit here the asymmetry is reversed. In the default case, assertions are uttered in contexts in which the speaker assumes that they know something that the addressee does not know. Rising polar interrogatives are licensed in contexts in which the speaker assumes that the addressee can supply the information that the speaker does not have at the point of utterance. Of course, there are contexts in which we ask such questions although it turns out that the addressee cannot supply an answer. Likewise, there are contexts in which we assert a belief that the other person already shares. If this was unknown to the speaker, the addressee will let the speaker know that their assumptions about the initial knowledge asymmetry was wrong. Our model only captures the simplest case, but we assume that this corresponds to assumptions about the normal course of a conversation that speakers and addressee share. Clark \& Wilkes-Gibbs (1986: 33) capture this assumption with the "principle of least collaborative effort":

(12) Principle of least collaborative effort: In conversation, the participants try to minimize their collaborative effort - the work that both do from the initiation of each contribution to its mutual acceptance. 
We assume that the principle of collaborative effort only holds for assertions as well as questions with an interrogative word order because here, the formand function mapping follows grammaticalized conventions.

Rising polar interrogatives serve well to demonstrate how syntax mediates between the different ingredients that are used to compose speech acts. We assume that commitment and engagement are hosted in the interactional structure: Commitment captures the grounding of a belief and therefore is realized in GroundP; engagement captures the response expectation and therefore is realized in ResponseP. Syntax mediates the contents of ResponseP, GroundP, and CP, where the latter hosts the propositional content, or sentence radical (Lewis 1972). We here assume the blueprint of the USH: two abstract arguments (such as times, events, and in the case at hand propositions and the interlocutor's grounds) are related by a coincidence feature ([ucoin]). We saw above that the USH assumes a universal architecture of hierarchically structured functions. The coincidence feature is at the core of how arguments are related to each other. For rising polarity questions this translates into a positive value ([+coin]) for engagement and to a negative value ([-coin]) for commitment, because the speaker cannot publicly commit to a proposition. Therefore they engage the addressee to resolve the choice between alternative propositions. In other words, the speaker's ground does not coincide with the propositional content. Instead, it is the addressee's ground which needs to coincide with the propositional content.

Syntactic configuration of rising polar interrogatives

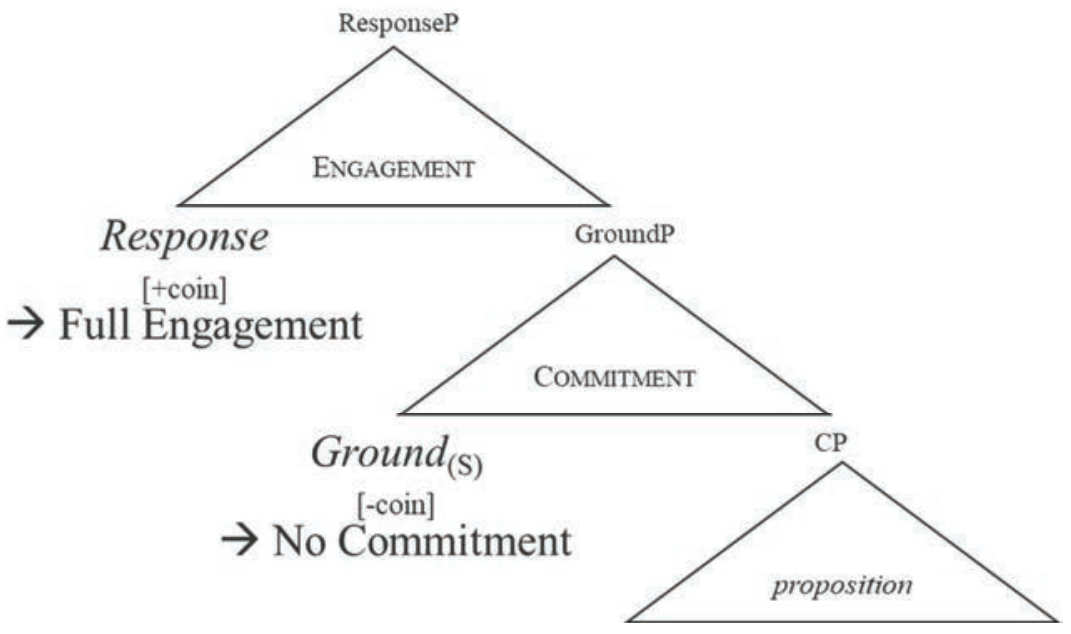

For polarity questions and assertions, we can summarize the possible configurations of commitment and engagement as in Figure 7. These configurations largely correspond to the simplified mapping of form and function we saw in previous accounts, repeated below as Figure 6 for ease of comparison. 


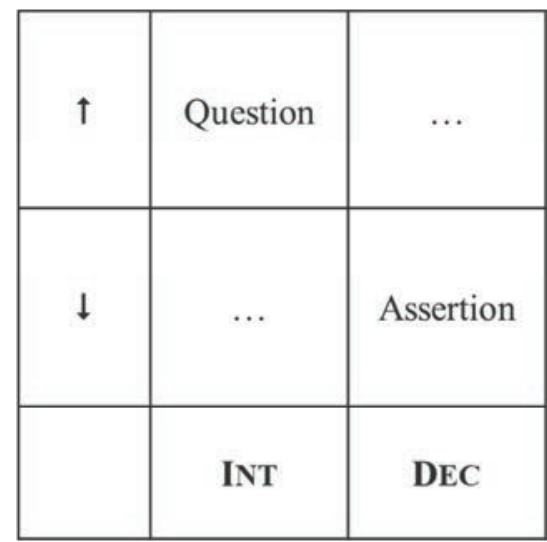

Figure 6: form-function mapping

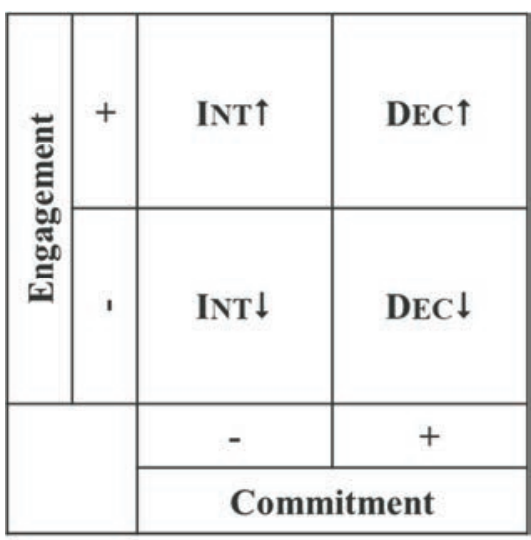

Figure 7: function-form mapping

\section{Deconstructing other phenomena associated with questionhood}

All other questions introduced in (1) and (2) above have configurations of commitment and engagement that are not inversely related to each other. We thereby build on the insight from Beyssade \& Marandin (2007) that engagement is independent of commitment, which helps us to address the apparent incompatibility with a call-on-addressee (to respond, confirm, or affirm) with a public commitment to the truth of the proposition. In terms of their form this corresponds to configurations with interrogative clausetype and falling SFI or declarative clause type with rising SFI. So how can we model the conversational effects of all the questions in (1) and (2)? Instead of distinguishing only positive and negative valuations of the coincidence feature, we assume that, unlike propositional structure, interactional structure also allows for unvalued coincidence features. This assumption is necessary, because some questions come with a biased or incomplete commitment. Consider the examples in (14), repeated from (1) and (2) above.

$$
\begin{array}{lll}
\text { a. } & \text { Who won? } & \left(\mathrm{H}^{\star} \mathrm{L}-\mathrm{L} \%\right) \\
\text { b. } & \text { She won? } & \left(\mathrm{L}^{*} \mathrm{H}-\mathrm{H} \%\right)
\end{array}
$$

The example in (14)a is a typical content question. The majority of content questions occur with a fall and therefore contrast with polarity questions, which standardly occur with a rise (Hedberg et al. 2017). Example (14) $\mathrm{b}$ is a declarative question, which also does not fit the unmarked encoding of questions. Both of these questions can neither be characterized by full commitment nor by no commitment. In content questions, most of the content is taken for granted except for the information captured by the whpronoun. In (14)a, it is presupposed that 'somebody won' (Ginzburg 2004), but the speaker cannot commit to an identification of the agent of winning because they lack this information. The evidential basis of open propositions, 
as in (14)a, do not allow the speaker to mark the type of commitment because the speaker cannot publicly commit to a proposition that misses information. The speaker may well be in the position to presuppose the truth a proposition that misses the information marked by the wh-pronoun, but this does not qualify the speaker to commit to it publicly. At the same time, the fact that the speaker is presupposing the truth of some of the information suggest that the speaker has some knowledge relevant to the utterance. Hence, it makes sense to allow for some middle ground between committing and not committing to the truth of a proposition.

Declarative questions, as in (14)b, also come with an unmarked commitment, albeit for a different reason. Both in content questions and in declarative questions, the speaker does not have sufficient evidence to allow them to publicly commit to a proposition. In declarative questions, however, the speaker is biased and no particular piece of information is missing. Although neither question in (14) allows the speaker to make a public commitment they both lack some evidence of the truth of a closed proposition - they differ in their type of engagement. In a content question, the addressee signals with the request not to engage that the truth of the proposition 'somebody won' is presupposed. Hence, the speaker of (14)a does not engage the addressee to resolve a choice between propositional alternatives. The missing information is sufficiently encoded by the wh-pronoun which requires the addressee to fill in that variable (due to standard conversational principles) and makes a different form of engagement redundant. The response requirement that we associate with content questions and other types of questions arises from the unmarked commitment, not from the particular type of engagement. In (14)b, however, the addressee is clearly engaged with the choice of propositional alternatives: either the referent won, or she did not. The bias toward the alternative that she won arises due to the declarative clause type which is standardly associated with assertions (e.g. Gunlogson 2003, 2008, Krifka 2015, Farkas \& Roelofson 2017). Interrogative word order always points to the presence of a choice between propositional alternatives.

With the addition of an unmarked feature configuration for commitment, which has an equivalent configuration for engagement in the context of a range of declaratives, the mapping of commitment and engagement has become a lot more complex. We not only have three different types of commitment and engagement; we also have configurations of commitment and engagement which are no longer in an inverse relation. For falling content questions and rising declarative questions, unmarked commitment combines with no engagement or full engagement, respectively. For the other questions in (1) and (2), we find further configurations of commitment and engagement, predicted by the system we have now in place. This includes the remaining questions repeated here as (15). 


$$
\begin{array}{ll}
\text { a. She won WHAT } \uparrow & \left(\mathrm{L}^{*}+\mathrm{H} H-\mathrm{H} \%\right) \\
\text { b. Who won (again) } \uparrow & \left(\mathrm{L}^{*} \mathrm{H}-\mathrm{H} \%\right) \\
\text { c. Did she win or lose } \downarrow & \left(\mathrm{H}^{\star} \mathrm{L}-\mathrm{L} \%\right)
\end{array}
$$

The example in (15)a is a so-called echo question whose content is treated as given except for the contrastively-marked element (Artstein 2002, Reis 2017). Echo questions come with a full commitment to an alternative to what has been proposed in the previous turn. If the stress falls on the whpronoun, this alternative is not specified (i.e. 'She won something else' in (15)a). This assumption is compatible with the view that content questions address an unrestricted set of propositional alternatives (see above). If the contrastive stress fall on a different constituent, this alternative is specified to not include that constituent (i.e. 'She won not X'). This public commitment to an alternative is paired with an engagement of the addressee, because the proposition is contrasted with a non-exhaustive set of alternatives (differing in only the possible referents of the wh-pronoun). Example (15)b is a rising content question whose context of use reintroduces the engagement towards the propositional choices and therefore combines the unmarked commitment with full engagement. As a consequence, its function is similar to that of an echo-question - albeit with a different type of commitment. Example (15)c is an alternative question whose content is defined by a set of alternatives (winning vs. losing). As with content questions, the truth of the open proposition 'she did something' is presupposed. Contrary to a content question, however, the set of alternatives is exhaustively listed. Correspondingly, the speaker cannot publicly commit to a proposition because they are confronted with a fixed choice. At the same time, the speaker does not engage the addressee in the truth of the open proposition. The response requirement arises from the presence of alternatives, which is exhaustively listed here. The interrogative word-order is another marker of the presence of alternatives, as in the case of content questions.

With the integration of the examples of (15) into the deconstruction of questions into their types of commitment and engagement, we complete our analysis of the different types of questions. The resulting mapping is a lot more complex than a mapping that is based on the typical question/assertion distinctions based on clause type and SFI.

At the syntactic level, however, the addition of unmarked commitment leads to less complexity. For content questions, for instance, the unmarked commitment translates into an unvalued coincidence feature. This results in the lack of coincidence between the propositional content and the speaker's ground (see Heim \& Wiltschko in press for details). 
We conclude our discussion of the conversational effects of questions with the overview of their configurations in Table 1.

\begin{tabular}{|l|l|l|l|}
\hline Question & Commitment & Engagement & Effect \\
\hline Polarity & none & full & Resolve $p$ v. $p$ \\
\hline Declarative & unmarked & full & Resolve $p$ \\
\hline Echo & full & full & Confirm $p$ \\
\hline Content & unmarked & none & Accept P-x \\
\hline Alternative & none & none & Accept $p$ v. $q$ \\
\hline
\end{tabular}

Table 1: Conversational effects of different types of questions

\section{Encoding commitment and engagement}

So far, we have not addressed the original motivation for the syntactization of speech acts. The previous sections have focussed on the effects of questions, which we decomposed into different types of commitment and engagement. The encoding of these variables is what we discuss in the remainder of this paper. We build on the analysis of response and discourse particles as illustrated in Figure 10 (see Heim \& Wiltschko 2016, Wiltschko 2017, to appear, for details). These particles can be decomposed into their grounding and response properties, which are encoded by the particles in combination with intonation. For questions that occur without particles, we assume that both commitment and engagement are encoded via intonation.

To derive the shape of the sentence-final contour, syntax computes the information in ResponseP and GroundP, which corresponds to the duration and the pitch excursion of the SFI, respectively. The coincidence features determine the corresponding types of commitment and engagement. For rising intonation, duration negatively correlates with commitment and excursion positively correlates with engagement (see Fletcher \& Loakes 2010, Tomlinson \& Fox-Tree 2011, and Heim 2019b for quantifiable evidence). For falling intonation, the encoding seems to be reversed: longer duration corresponds to greater engagement and lower excursion corresponds to greater commitment (Heim 2019b). This inverse may well be the consequence of the physiological properties of prosody (Vassiere 2005) since a continuation of relaxing or straining of the vocal cords may be the most economical way to call for the addressee's attention. While both excursion and duration contribute to the encoding of interaction, their effects can be clearly separated. Figure 8 visualizes how commitment and engagement map unto the prosodic variables of excursion and duration in the context of rising declaratives. A decrease 
in excursion correlates with a smaller sense of engagement. An increase in duration correlates with a greater sense of commitment. This explains, for instance, the different addressee activation in low- vs. high-rising declaratives and why high-rising questions are often associated with insecurity.

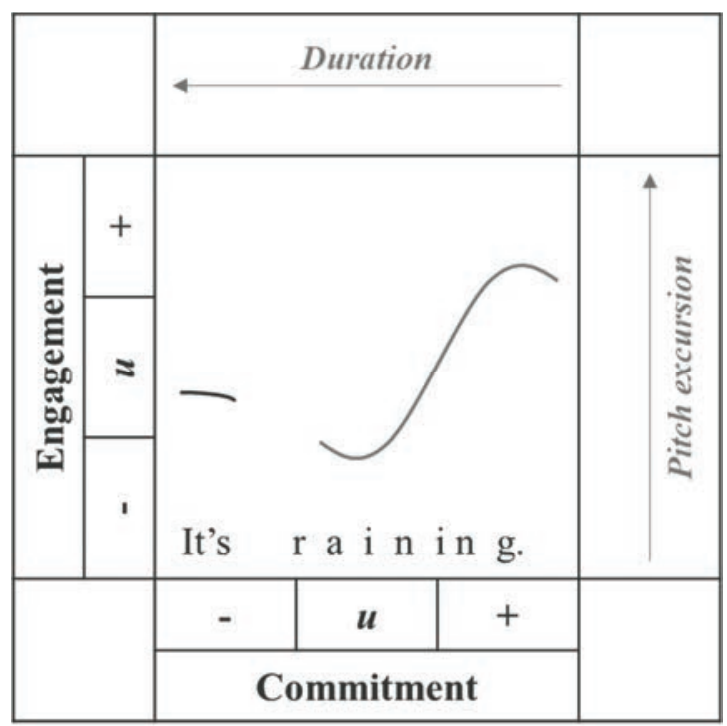

Figure 8: Mapping of commitment and engagement in rising declaratives

Syntax, then, serves to mediate between intonation and clause type in a more complex way than is predicted from a simple fall/rise and declarative/ interrogative distinction. The complexity in function has a corresponding complexity in form. The representation in (16), which visualizes the computation of the valuations of [ucoin] in ResponseP and GroundP, matches the representation of the prosodic variation of rising declaratives in Figure 9. Depending on the feature valuation of [ucoin] in GroundP, the duration of the rise is either long $([-$ coin $])$, short $([+$ coin $])$ or somewhere in-between if [ucoin] remains unvalued. The equivalent holds for of [ucoin] in ResponseP. The excursion of the rise is either low ([-coin $])$, high ([+coin $]$ ) or somewhere in-between if [ucoin] remains unvalued. Syntax serves to combine the information about pitch duration and excursion (encoding commitment and engagement) to manipulate the shape of the sentence-final tune. 
Syntactic mediation of forms and functions for speech acts with rising intonation

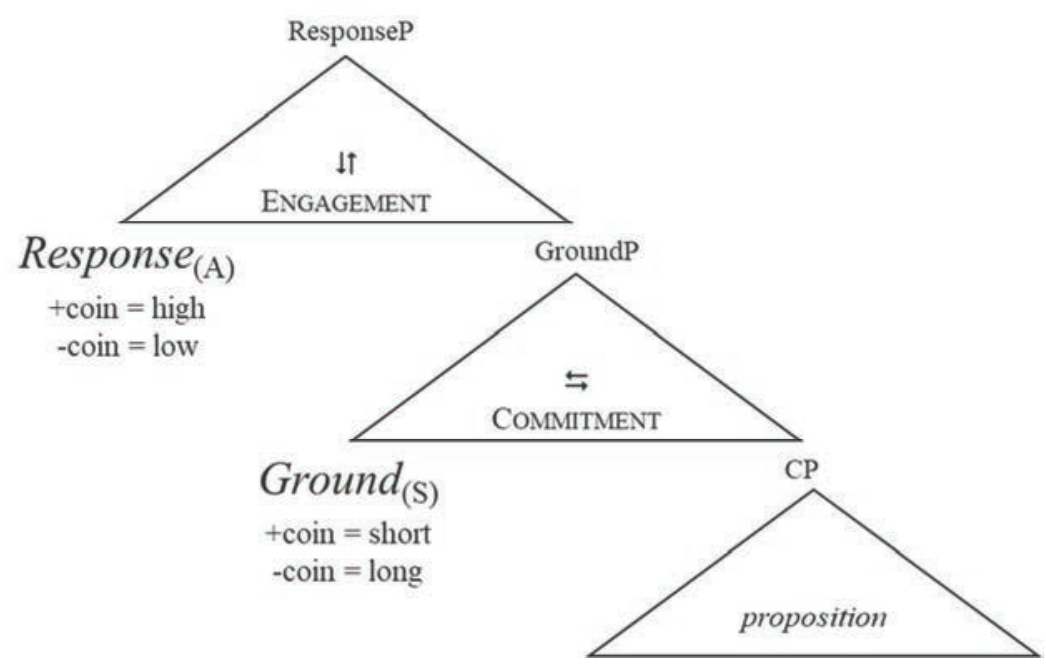

All the speech acts associated commonly with the notion of questionhood are therefore complex speech acts that communicate the speaker attitude, the expectation toward the addressee on how to respond, and a choice of different propositional alternatives. Since both commitment and engagement affect the shape of SFI, a syntactic integration of these variables is necessary to explain their relation to each other and to the propositional content. Speech acts are an interface phenomenon because morphosyntactic and prosodic information are linked to the interlocutors for their interpretation. There is a long tradition in syntactic analysis to recognize the importance of integrating discourse phenomena (e.g. Ross 1970, Rizzi 1997) and the present account is an advancement of this tradition that gives greater importance to the role of the interlocutors in deriving the meaning of utterances.

\section{Questions do not form a natural class; assertions do not either}

We have argued for a deconstruction of questions into different configurations of commitment and engagement. We have demonstrated that questions, at least those that are standardly treated in formal linguistic accounts, do not form a natural class - not in form, not in function, and not in their mappings of form and function. We can use the same variables to model questions, assertions, and speech acts that share characteristics of both. All of these speech acts communicate whether the speaker is ready to commit to the truth of a proposition in public and whether they expect the addressee to provide a resolution to a propositional choice. What we standardly describe as questions (which really only fits the effects of polarity questions) can therefore be paraphrased with 'I cannot commit to either $\mathrm{p}$ or $\neg \mathrm{p}$ and I expect you to resolve that choice'. Since no specific configuration or type is unique to 
questions or assertions, we argue that these speech act categories need to be reconceptualized independent from a question/assertion distinction. The gain from such an analysis is a broader concept of speech acts that allows us to compare the effects of questions and assertions independently of their clause types. The free combination of the degrees of commitment and engagement also allows us to derive the effects of a declarative with a highrise contour (Dec $\nearrow$ ), declaratives with a rise-fall-rise contour (Dec $\downarrow \nearrow$ ) and declaratives or interrogatives with a continuation rise (XP $\nearrow$ ). Figure 9 summarizes the combinations of commitment and engagement as predicted by the configurations allowed by the coincidence features in ResponseP and GroundP.

\begin{tabular}{|c|c|c|c|c|}
\hline \multirow{3}{*}{ 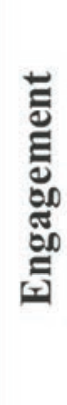 } & + & $\mathrm{INT} \uparrow$ & DEC $\uparrow$ & $\mathrm{XP} \uparrow$ \\
\hline & $\approx$ & $\begin{array}{c}\text { DEC } \\
\downarrow \nearrow\end{array}$ & $\mathrm{XP} r$ & $\mathrm{DEC} \nearrow$ \\
\hline & ' & $\begin{array}{l}\text { INT } \\
\nearrow \downarrow\end{array}$ & $\begin{array}{l}\text { WH- } \\
\text { INT } \downarrow\end{array}$ & DEC $\downarrow$ \\
\hline & & - & $\boldsymbol{u}$ & + \\
\hline & & \multicolumn{3}{|c|}{ Commitment } \\
\hline
\end{tabular}

Figure 9: Extending the account to declaratives not associated with questions

The extension of the account to non-questions is based on the same variables that we used for the deconstruction of questions. This extension is possible because intonation plays a key role in encoding commitment and engagement in English. The range of speech acts captured by our analysis surpasses any inventory of previous speech act accounts that rely on a direct mapping of form and function. So, despite the intuitive nature of the terms of questions and assertions, we propose that these terms refer to a range of conversational phenomena whose effects are best captured by the variables of commitment and engagement. 


\section{Notes}

1 We thank the audience of the Given! workshop at UBC in honor of Michael Rochemont, members of UBC's eh lab, and the audience of the special workshop on speech acts at SPE 10 for their helpful feedback.

2 The data discussed here largely corresponds to those in the literature concerned with the syntactic and prosodic form of speech acts (e.g. Bartels 1997, Gunlogson 2003, Truckenbrodt 2012, Farkas \& Roelofsen 2017).

3 We refer the reader to Wiltschko \& Heim in press for a treatment of tag questions, which builds on the same variables, commitment, and engagement.

4 Others have argued for a non-exhaustive set of response possibilities (e.g. Biezma \& Rawlins 2012).

5 The possibility of cancellation is the root of notable disagreemt the literature on how to define the nature or presumed knowledge: Katz and Postal 1964; Karttunen \& Peters 1976; and Comorovski 1996 argue for an implicature; and Groenendijk \& Stokhof 1984; Ginzburg 2004 for a presupposition.

6 One anonymous reviewer suggested that examples $3 \mathrm{~b}$ and $3 \mathrm{c}$ are meta-communicative expressives whose interpretation is owed to the high tones of the final contour. While we agree that both phenomena have a meta-communicative function they nevertheless need to be accounted for in a typology of questions. Just as (4) a, these questions are variants of so-called echo questions whose relation to other questions is frequently discussed (Bolinger 1957; Blakemore 1984; Ginzburg \& Sag 2000; Sobin 1990, 2010, Arstein 2002; Reis 2017). To exclude them from our analysis would not do justice to the range of functions that questions may bear.

7 Alternatives in falling polarity questions are similarly complementary. Hedberg et al. (2017) present the following corpus example: "Yes or no answer. Will Michael Bloomberg be able to fill Giuliani's shoes?". Just as the example in (4)c, this corpus example ends in a fall. Complementary alternatives are not exclusive to polarity questions. Bartel's (1997) example Do I turn right or left? is just as complementary as our example in (4)c.

8 This is in the spirit of Frege's (1884) principle of contextuality according to which the meaning of a word can only be understood in the context of a sentence, not in isolation. This principle is widely acknowledged in the functional tradition while in the generative tradition, it is Frege's principle of compositionality which is typically modelled. Wiltschko's 2014 approach explicitly tries to bridge these two traditions by building function into syntactic structure.

9 We treat declarative questions separately from so-called echo questions due to their different prosodic profile. Echo questions mandatorily include contrastive stress on a constituent or morpheme (Reis 2017). The rise can also begin much earlier in the sentence, which has led some researchers to postulate a different analysis of the nuclear tune, i.e. $\mathrm{L}+\mathrm{H}^{\star} \mathrm{H}-\mathrm{H} \%$ (Sobin 1990; Artstein 2002) instead of a $\mathrm{L}^{\star} \mathrm{H}-\mathrm{H} \%$ contour (Bartels 1997).

${ }_{10}$ We are grateful for the comment of an anonymous reviewer that the bias may arise on behalf of the addressee if the rising declaratives echoes a previous assertion. We submit that this is the case in echo questions, which have different types of commitment. Echo questions do not express a bias; they express a disbelief.

11 For a more detailed motivation of the integration of speech acts into the domain of syntax, see Speas \& Tenny 2003, Hill 2007, Hageman \& Hill 2013, Wiltschko \& Heim 2016, Heim \& Wiltschko, in press and Wiltschko to appear. 


\section{References}

Allan, Keith. 2006. Clause-type, primary illocution, and mood-like operators in English. Language Sciences, vol. 28, p. 1-50.

Artstein, Robert. 2002. A focus semantics for echo questions. Workshop on information structure in context. IMS, University of Stuttgart, p. 98-107.

Auer, Peter. 2002. Projection in conversation and projection in grammar. InLiSt33, www. inlist. uni-bayreuth. de/issues/33/Inlist33. pdf.

Austin, John. L. 1962. How to Do Things with Words. The William James Lectures Delivered at Harvard University in 1955; edited by J. O. Urmson. Oxford: Clarendon Press.

Bartels, Christine. 1997. Towards a compositional interpretation of English statement and question intonation. Amherst, MA: University of Massachusetts dissertation.

Bavelas, Janet. B., Jong, P. D., Korman, H., \& Jordan, S. S. 2012. Beyond back-channels: A three-step model of grounding in face-to-face dialogue. In Feedback Behaviors in Dialog 2012, 5-6.

Beyssade, Claire \& Jean-Marie Marandin. 2006. The speech act assignment problem revisited: Disentangling speaker's commitment from speaker's call on addressee. Empirical issues in syntax and semantics, vol. 6, p. 37-68.

Bhat, Darbhe Narayana Shankara. 2000. The indefinite-interrogative puzzle. Linguistic Typology, vol. 4, p. 365-400.

Biezma, María, and Kyle Rawlins. 2012. Responding to alternative and polar questions. Linguistics and Philosophy, vol. 35, 5, p. 361-406.

Blakemore, Diane. 1994. Echo questions: A pragmatic account. Lingua, vol. 94, 4, p. 197-211.

Bolinger, Dwight. 1957. Interrogative Structures of American English: The Direct Question. Publ. Am. Dialect Soc. 28. University of Alabama Press, Birmingham.

Borchmann, Simon. 2020. The intentionality of questions - a critique of Searle's analysis of speech acts. Scandinavian Studies in Language, 11(1), 20-55.

Chomsky, Noam. 1995. The minimalist program (Vol. 28.). Cambridge, Mass: The MIT Press.

Clark, Herbert H., and Susan E. Brennan. 1991. Grounding in communication. Perspectives on socially shared cognition, vol.13, p. 127-149.

Comorovski, Ileana. 1996. The Interpretation of Interrogative Phrases. In Interrogative Phrases and the Syntax-Semantics Interface. Dordrecht: Springer, Chapter 2, 6-54.

Farkas, Donka F. \& Floris Roelofsen. 2017. Division of labor in the interpretation of declaratives and interrogatives. Journal of Semantics, vol. 34, 2, p. 237-289.

Frege, Gottlob. 1884. Die Grundlagen der Arithmetik. Eine logisch-mathematische Untersuchung über den Begriff der Zahl. Breslau: Verlag Wilhelm Koebner.

Fletcher, Janet \& Deborah Loakes. 2010. Interpreting rising intonation in Australian English. Proceedings of Speech Prosody, Chicago, IL.

Ginzburg, Jonathan \& Ivan Sag. 2000. Interrogative investigations. Stanford: CSLI publications.

Ginzburg, Jonathan. 2004. A quasi-naive semantics for interrogatives and its implications. J. Gutierrez-Rexach (ed.) Semantics: Critical concepts in linguistics. London: Routledge, 353-373. 
Grice, H. Paul. 1978. Further notes on logic and conversation. P. Cole (ed.), Syntax and Semantics 9: Pragmatics. New York: Academic Press, 113-128.

Groenendijk, Jeroen, Antonius Gerardus \& Martin Johan Bastian Stokhof. Studies on the Semantics of Questions and the Pragmatics of Answers. Diss. Univ. Amsterdam, 1984.

Gunlogson, Christine. 2003. True to form: Rising and falling declaratives as questions in English. New York: Routledge.

Gunlogson, Christine. 2008. A question of commitment. Belgian Journal of Linguistics, vol. 22, p. 101-136.

Haegeman, Lililane \& Virginia Hill. 2013. The syntacticization of discourse. R. Folli, C. Sevdali and R. Truswell (eds.) Syntax and its limits. Oxford: Oxford University Press, 370-390.

Hamblin, Charles L. 1958. Questions. Australasian Journal of Philosophy, Vol. 36. p. 159-168.

Hausser, Roland R. 1983. The syntax and semantics of English mood. F. Kiefer (ed.). Questions and answers. Dordrecht: Springer, 97-158.

Hedberg Nancy, Juan M. Sosa and Emrah Görgülü. 2017. The Meaning of Intonation in Yes-No Questions in American English: A Corpus Study. Corpus Linguistics and Linguistic Theory, vol. 13, 2, p. 1-48.

Heim, Johannes \& Martina Wiltschko. to appear. Interaction at the prosody-syntax interface. Accepted for publication in: G. Kentner \& J. Kremers (Eds.) Prosody in syntactic encoding: Special Issue in Linguistische Arbeiten. De Gruyter.

Heim, Johannes, Hermann Keupdjio, Zoe Wai-Man Lam, Adriana Osa-Gómez, Sonja Thoma \& Martina Wiltschko. 2016. Intonation and particles as speech act modifiers: A syntactic analysis. Studies in Chinese Linguistics, vol. 3, p. 109-129.

Heim, Johannes. 2019a. Turn-peripheral management of Common Ground: A study of Swabian gell. Journal of Pragmatics, vol. 141, p. 130-146.

Heim, Johannes. 2019b. Commitment and Engagement. The role of intonation in deriving Speech Acts. PhD dissertation, UBC.

Hill, Virginia. 2007. Vocatives and the pragmatics-syntax interface. Lingua 117.12: 2077-2105.

Karttunen, Lauri \& Stanley Peters. 1979. Conventional implicature. Syntax and semantics, vol. 11, p. 1-56.

Karttunen, Leni. 1977. Syntax and semantics of questions. Linguistics and philosophy, vol. 1, 1, p. 3-44.

Katz, Jerrold J. \& Paul M. Postal. 1964. An Integrated Theory of Linguistic Descriptions. Cambridge, MA: MIT Press.

Krifka, Manfred. 2015. Bias in Commitment Space Semantics: Declarative questions, negated questions, and question tags. S. D’Antonio, M. Moroney \& C. Rose Little (eds.), Semantics and Linguistic Theory (SALT) 25. Washington, D.C: LSA Open Journal Systems, 328-345.

Lee, Patricia. 1974. Perlocution and illocution. Journal of English linguistics, vol. 8, 1, p. 32-40.

Levinson, Stephen C. 1983. Pragmatics. Cambridge textbooks in linguistics. Cambridge University Press. 
Lewis, David. 1972. General semantics. D. Davidson \& G. Harman (eds.) Semantics of natural language. Dordrecht: Springer, 169-218.

MacFarlane, John. 2011. What is assertion? J. Brown and H. Cappelen (eds.), Assertion. New philosophical essays. Oxford: Oxford University Press, 79-96.

Malamud, Sophia A. \& Tamina Stephenson. 2014. Three ways to avoid commitments: Declarative force modifiers in the conversational scoreboard. Journal of Semantics, vol. 32, 2, p. 275-311.

Montague, Richard. 1974. Formal Philosophy, ed. R. Thomason. New Haven.

Nielsen, Niels Møller. 2020. Expanding Searle's analysis of interrogative speech acts: A systematic classification based on preparatory conditions. In Scandinavian Studies in Language, 11(1), p. 7-19.

Portner, Paul. 2004. The semantics of imperatives within a theory of clause types. Semantics and linguistic theory, vol. 14, p. 235-252.

Reis, Marga. 2017. On the analysis of echo questions. Florida Linguistics Papers, vol. 4, 3.

Roberts, Craige. 1996. Information structure in discourse: Towards an integrated formal theory of pragmatics. In Yoon, J. H. \& Andreas Kathol (eds.), OSU Working Papers in Linguistics 49: Papers in Semantics. Columbus: The Ohio State University, 91-136.

Rudin, Deniz. 2018. Rising above commitment. Doctoral dissertation, UC Santa Cruz)

Sadock, Jerrold M. \& Arnold M. Zwicky. 1985. Speech act distinctions in syntax. Language typology and syntactic description, vol. 1 p. 155-196.

Sadock, Jerrold M. 1974. Toward a linguistic theory of speech acts. Cambridge, MA: Academic Press.

Searle, John R. 1975. Indirect speech acts. Speech acts. Leiden: Brill, Chapter 3, 59-82.

Searle, John. R. 1975. A taxonomy of illocutionary acts. Minneapolis: University of Minnesota Press.

Silverman, Kim, Marym Beckman, John Pitrelli, Mari Ostendorf, Colin Wightman, Patti Price \& Julia Hirschberg. 1992. ToBI: A standard for labeling English prosody. In Second international conference on spoken language processing.

Sobin, Nicholas. 1990. On the syntax of English echo questions. Lingua, vol. 81, p. 141-167.

Sobin, Nicholas. 2010. Echo questions in the Minimalist Program. Linguistic Inquiry, vol. 41, 1, p. 131-148.

Speas, Peggy and Carol Tenny. 2003. Configurational Properties of Point of View Roles. A. DiSciullo (ed.) Asymmetry in Grammar. Amsterdam: John Benjamins, 315-343.

Stalnaker, Robert. 1978. Assertion. P. Cole (ed.), Syntax and Semantics, vol. 9: Pragmatics. Cambridge, MA: Academic Press, 315-332.

Stalnaker, Robert. 2002. Common ground. Linguistics and philosophy 25, Vol. 5, p. 701-721.

Stalnaker, Robert. 2014. Context. Oxford: Oxford University Press.

Stenius, Erik. 1967. Mood and language game. Synthese, vol. 17, 1, p. 254-274 
Tomlinson, John M. Jr. \& Jean E. Fox Tree. 2011. Listeners' comprehension of uptalk in spontaneous speech. Cognition, vol. 119, 1, p. 58-69.

Vaissière, Jacqueline. 2005. Perception of intonation. In Pisoni, David \& Robert Remez (eds.), The Handbook of Speech Perception. Oxford: Blackwell, 236-263.

Westera, Matthjis. 2019. Rise-Fall-Rise as a Marker of Secondary QUD s. In Daniel Gutzmann \& Katharina Turgay (eds.), Secondary content: The semantics and pragmatics of side issues. Leiden: Brill, 376-404.

Williams, Edwin. 1994. Thematic Structure in Syntax. Cambridge, MA: MIT Press

Williams, Edwin. 1981. Argument structure and morphology. The linguistic review, vol. 1, 1, p. 81-114.

Wiltschko, Martina \& Johannes Heim. 2016. The syntax of confirmationals. In Günter Kaltenböck, Evelyn Keiyser \& Arne. Lohrmann, Outside the Clause: Form and function of extra-clausal constituents. Amsterdam: John Benjamins Publishing Company, 305-340.

Wiltschko, Martina, Derek Denis \& Alexandra D’Arcy. 2018. Deconstructing variation in pragmatic function: A transdisciplinary case study. Language in Society, vol. 47, 4, p. 569-599.

Wiltschko, Martina. 2014. The universal structure of categories: Towards a formal typology. Cambridge: Cambridge University Press.

Wiltschko, Martina. 2017. Ergative constellations in the structure of speech acts. In Jessica Coon, Diane Massam \& Lisa deMena Travis (eds.), The Oxford Companion to Ergativity, Oxford: Oxford University Press.

Wiltschko, Martina. To appear. The grammar of interactional language. Towards a formal typology. Cambridge University Press. 